\title{
Galactose epimerase deficiency
}

INSERM

\section{Source}

INSERM. (1999). Orphanet: an online rare disease and orphan drug data base. Galactose epimerase deficiency. ORPHA:79238

Galactose epimerase deficiency is a very rare, moderate to severe form of galactosemia (see this term) characterized by moderate to severe signs of impaired galactose metabolism. 